\title{
Congruence Couple Therapy for Pathological Gambling
}

\author{
Bonnie K. Lee, Ph.D. \\ School of Health Sciences, University of Lethbridge, 4401 University Drive, \\ Lethbridge, AB, T1K 3M4, Canada. \\ e-mail: bonnie.lee@uleth.ca Tel. (403) 317-5047 Fax (403) 329-2668
}

This paper was first published on January 4, 2008 in the International Journal of Mental Health and Addiction (2008 Online First). The original publication is available at http://www.springerlink.com/. (DOI: 10.1007/s11469-007-9137-x)

\begin{abstract}
Couple therapy models for pathological gambling are limited. Congruence Couple Therapy is an integrative, humanistic, systems model that addresses intrapsychic, interpersonal, intergenerational, and universal-spiritual disconnections of pathological gamblers and their spouses to shift towards congruence. Specifically, CCT's theoretical foundations, main constructs, and treatment interventions are illustrated in a progression of six clinical phases. Promise of CCT's systemic conceptualization and interventions for pathological gambling and future directions in its continuing evolution are discussed.
\end{abstract}

Keywords: Congruence Couple Therapy . Pathological gambling . Couple therapy . Humanistic . Experiential . Spiritual . Virginia Satir

\section{Introduction}

Marital distress among pathological gamblers has been flagged as an issue for clinical attention for nearly two decades (Ciarrocchi and Hohmann 1989; Lorenz and Yaffee 1988; McCown and Chamberlain 2000; Steinberg 1993). Yet literature reviews reveal that evidence-based models available for problem gambling treatment remain predominantly cognitive-behavioural, relying on individual conceptualizations and interventions (Oakley-Browne et al. 2004; Toneatto and Ladouceur 2003; Toneatto and Millar 2004). When attention is drawn to the distress suffered by spouses of pathological gamblers, the focus is largely on segregated support for the spouses, e.g. GamAnon, and individually-based interventions for spouses (Heineman 1994, 2001; Makarchuk et al. 2002). A paucity of treatment models utilizing systemic conceptualization and interventions with conjoint couple approaches exists (Grant-Kalischuk et al. 2006; Nathan 2005; Petry 2005).

To fill this couple therapy gap in treating pathological gambling, Congruence Couple Therapy (CCT) has been developed as a short-term, integrative, humanistic, systemic approach in working with couples, not only in curbing problem gambling, but in further addressing the factors that underlie the problem (Lee 2002a; Lee and Rovers 2008, forthcoming). What is proposed is a model that can make inroads into healing the depth of woundings and traumatic history of pathological gamblers (Lee 2002a; Petry and Steinberg 2005), hurts and wounds in spouses (Dickson-Swift et al. 2005; Lorenz and Yaffee 1989), and the severe fractures in the couple relationship. Promise of CCT's effectiveness has been indicated in two early empirical studies. First, findings from an 
initial in-depth clinical study of eight couples of pathological gamblers and spouses yielded positive results with mixed methods (Lee 2002a). Subsequently, 21 problem gambling counsellors were trained to apply CCT to 24 couples (Lee et al. 2006, 2008, forthcoming; Lee and Rovers 2008, forthcoming). Again, the triangulated, mixed methods findings from couples' and counsellors' self-reports were encouragingly positive (Lee 2002a; Lee et al. 2006, 2008, forthcoming; Lee and Rovers 2008, forthcoming). A larger, randomized control efficacy study of CCT is currently proposed.

The purpose of this paper is to present the philosophical, conceptual, and clinical components of Congruence Couple Therapy. A composite clinical case based on three couples drawn from the aforementioned empirical research (Lee 2002a; Lee et al. 2006) illustrates the CCT process in six phases or movements.

\section{Background to Congruence Couple Therapy}

Congruence Couple Therapy is a compact, short-term therapy model developed by the author based on a systematization of Virginia Satir's pioneering work in family therapy (Satir et al. 1991). While recognized for her charisma and popular appeal, Satir's work has been critiqued as lacking theoretical structure and a clear guide to clinical application (Brubacher 2006; Nichols and Schwartz 1995). Without a coherent framework, Satir's contributions risk being regarded as a "mere collection of creative techniques" (Brubacher 2006, p.141). CCT offers philosophical and conceptual grounding, as well as clinical structure and specificity to what was implicit and intuitive in Satir. In an "era of evidence" that marks the beginning of the twenty-first century (Sexton et al. 2003, p.460), therapeutic inquiry has moved from considering the broad efficacy of couple therapy to the refined questions of: (1) What specific model of therapy, (2) For what clinical problem, (3) With what interventions and, (4) In what context (Sexton et al. 2003). For such purpose, a therapeutic model needs to articulate its theoretical assumptions and conceptual framework, specify its key interventions that can be taught and replicated, then applied to specific clinical problems whose process and outcomes can be studied.

The impetus for the development of Congruence Couple Therapy arose out of the recognized need to address the roots of pathological gambling and the immense distress of both pathological gamblers and their spouses, distress that in many cases has been present even before the gambling problem began. Thus, pathological gambling is the tip of the iceberg, a symptom that is a "cry for help" by the gambler inextricably entangled in the family system both past and present of which he/she is a part. CCT aims not only at abstinence or harm reduction in relation to gambling, but further works in opening up a reservoir of psycho-social resources for the pathological gambler and his/her significant relationships. The net effect is to displace pathological gambling and the functions it serves. A "second-order change" (Watzlawick et al. 1974) in the system in which the gambler is most centrally involved places the gambler in a strong position to maintain his/her gains from treatment. The gambler then becomes the captain of his/her own ship rather than one just bailing the water as the ship flounders. 
In the conjoint space of CCT, pervasive difficulties of pathological gamblers come to light. These include: the legacy of childhood trauma (Lee 2002a; Petry and Steinberg 2005; Scherrer et al. 2007); social isolation (Wiebe et al. 2001); reduced coping capacity (Lightsey and Hulsey 2002;McCormick 1994; Monacietal. 2005; Petry et al. 2007); low self-esteem (Lee 2002a; Monaci et al. 2005); and other forms of addiction and mental health disorders (Coman et al. 1997; Petry et al. 2005). Spouses of gamblers suffer financially, physically, mentally and emotionally upon the sudden and devastating discovery of pathological gambling and its aftermath (Dickson-Swift et al. 2005; Lorenz and Yaffee 1988, 1989). Furthermore, both gamblers and spouses are found to display verbal inhibition, anxiety symptoms, and avoidance of feelings (Savron et al. 2003). Noteworthy are clinical indications that a history of traumatic childhood is not uncommon among spouses of gamblers (Lee 2002a). A couple-centred approach that has the potential to work with an intertwining of the above issues would be a valuable addition to the field.

\section{Philosophical Foundations}

\section{The Five Cornerstones}

Every model of psychotherapy premises on a number of major tenets and assumptions about human beings, although they are not always explicitly articulated. These tenets guide the interventions of a given therapy model. CCT rests on five philosophical cornerstones that have informed therapeutic traditions: systemic, humanistic, existential, experiential, and social constructionist. The essential features of these philosophical propositions are delineated with their major proponents as follows:

\section{Systemic}

Nothing exists in isolation; everything is interrelated. The change in one element in a system affects all other elements therein. Systems is a way of seeing and thinking that emphasizes the patterns of interrelationships and interaction of parts in relation to the whole (Bateson 1972; Von Bertalanffy 1968). The way elements interact in a system leads to an outcome. Therefore, the change in one element in the system or its interaction leads to a new outcome. One can leverage change in a system and anchor its stability at a new level by shifting individual or multiple elements simultaneously, sequentially and strategically. This approach contrasts with the assumptions of a linear, individualist, reductionist orientation. As systems are embedded within systems, we have microsystems operating within macro-systems, such as the family within a larger socio-cultural context. Sub-systems interact, an intrapsychic system of thoughts and feelings, for example, is linked to the interpersonal system of action and communication. In turn, the outer interpersonal system also has an impact on the inner psychological system of thoughts, feelings, and beliefs.

\section{Humanistic}

Humanistic therapy is predicated upon the human potential for growth, healing, 
awareness, and actualization (Cain 2002;Maslow 1968;Rogers 1961; Satir et al. 1991). It privileges the creative potential of human beings to move in a life-enhancing direction (Meador and Rogers 1984; Rogers 1961). Spirituality has been a recurrent theme in the humanistic tradition (Elkins 2001;Maslow 1968; Satir 1988). In its essence, spirituality speaks to our relationship with the energy and spirit within and our recognition of its sacredness and power. The spirit however, is not separate from the human. Spirit is intrinsic to being human. It is that which gives humanity depth and vitality. The human organism is therefore conceived of as a gestalt - an interconnected, indivisible whole of body, mind, and spirit (Cain 2002; Perls et al. 1951; Seeman 2002).

\section{Existential}

Less salient to humanistic therapy is the acknowledgment of the limits of existence and human fallibility. Balancing the optimism of the humanists, the existentialists acknowledge the tragic dimension of existence, the grand potential of humanity fallen short (Remen et al. 1985; Tillich 1967). However, even in the midst of limiting conditions, choice and responsibility play a central role in human becoming (Frankl 1953; May 1953, 1981). Human destiny is therefore not closed but open, hinging on the exercise of our choosing. The unfolding of this becoming is believed to have directionality towards purpose, meaning and fulfillment (Frankl 1953; May 1981).

\section{Experiential}

Experiential psychotherapy privileges a way of attending to the bodily inner experience of the person which incorporates his/her interaction with the environment (Gendlin 1981). By attending to the inner experience mediated through the body, one gains access to deeper layers of meaning through opening up the human organism to the emergent (Gendlin 1981;Hendricks 2002). An experiential way of knowing concentrates on the bodily "felt sense" in the here-and-now (Gendlin 1981, p. 10). Attending to this immediacy in the body heightens the internal process for an organic unfolding of experiencing and change (Gendlin 1974).

\section{Social Constructionist}

We liveinasocial worldofmeaning and knowledge constructed through shared language, symbols, rules and norms. This worldview, though socially constructed, has the guise of taken-for-granted facticity (Berger and Luckmann 1967). Socialization is the process by which collectively constructed "reality" is internalized by individuals within a society (Berger and Luckmann 1967). In turn, internalized social constructs exert power in shaping how we think, feel, value, and behave. As a microcosm of culture and society, the family transmits in its communication and interactions the beliefs, values, and practices of the larger society (Satir 1988). Hence, the family is a potent vehicle of socialization. The corollary is that social realities can be intentionally re-constructed through narratives and symbols by recruiting others as participants and witnesses through conversations and performance (Anderson and Goolishian 1988; Gergen 1985; Lee and Nixon 2007; White and Epston 1990). Therefore, families, groups, and communities of 
shared reconstructed discourses can create new realities as seeds of social change (Lee 2002d).

\section{Person as an Inter-related Four Dimensional System}

CCT utilizes a four-dimensional, systems-based conceptual model of the person to guide interventions (see Fig. 1). Intrapsychic, interpersonal, intergenerational and universalspiritual dimensions are conceptualized as interconnected and mutually influential (Lee 2002a, b, c, 2003).

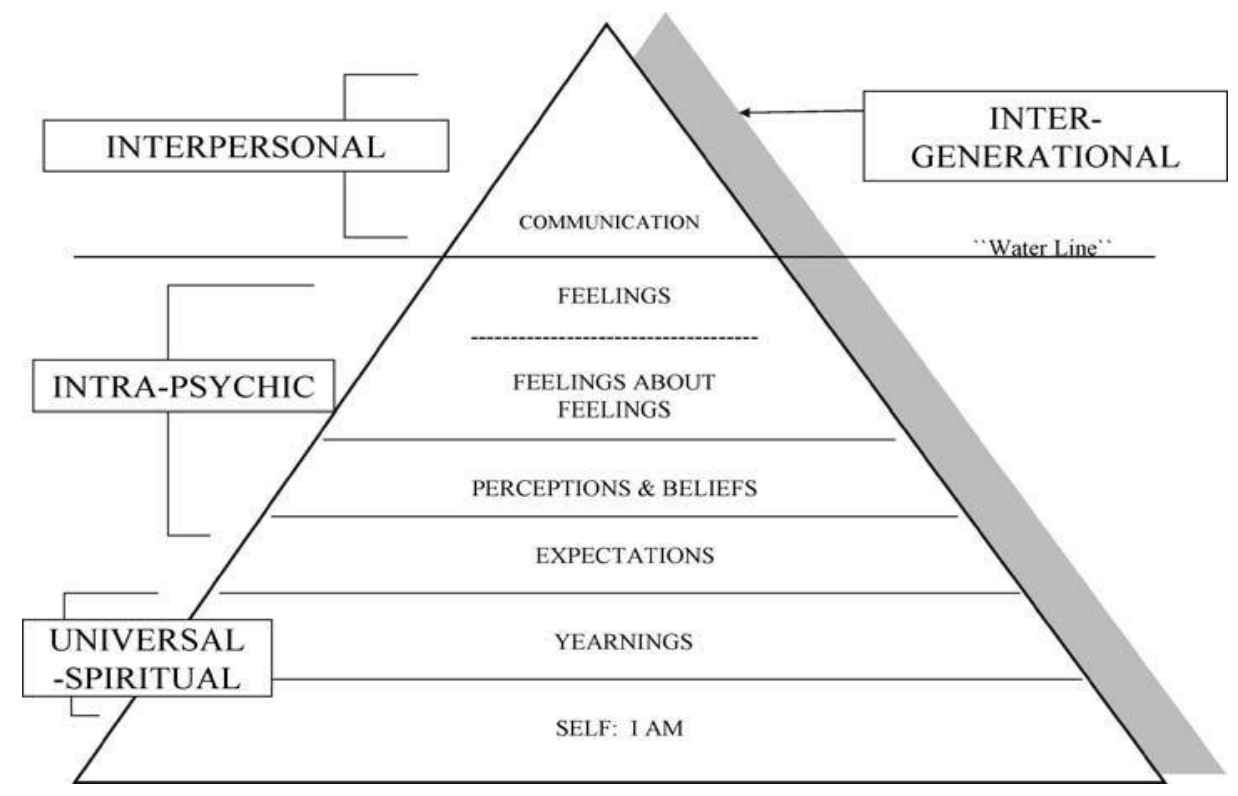

Figure 1: The Iceberg: Four interrelated human dimensions (advanced conceptualization of Satir et al., 1991; Banmen 1994; Lee 2002b)

Intrapsychic

The inner experience of a person makes up the intrapsychic dimension and this dynamic system includes feelings, feelings about the feelings, perceptions, beliefs, and expectations (Satir et al. 1991). Furthermore, our perceptions, beliefs, feelings and expectations are informed by our past experiences, social and cultural rules, values, and narratives. The different components of inner experience are in interaction with one another, for example, perceptions influence beliefs, and beliefs influence feelings. Together the interplay of elements gives rise to how we behave and communicate and how we conduct ourselves in the interpersonal world.

Intergenerational

We are people with a history that influences our present, although we are not determined 
by it. Communication, behaviours, values, beliefs, pervasive modes of feeling and interaction in our family of origin find their way into our present and ways of construing the world. In CCT, understanding patterns of the past illuminates awareness of present functioning. Appreciating the humanity of ancestral figures who have shaped us allows us to become reconnected with them. Therefore, examining one's family of origin patterns allows a person to gain clarity into the emotional and cognitive strongholds of old patterns and to evaluate how well they are of service in the present. Our past constructs are therefore in need of regular re-assessment to meet the challenges of contemporary living.

\section{Universal-spiritual}

Despite socially constructed differences, people share a common humanity in their universal yearnings and aspirations. To belong, to love and be loved, to be accepted and respected, to live with meaning and purpose are some universal human yearnings that need to be honoured and validated. When our yearnings are acknowledged, we find ways and means to create the conditions in which they can be fulfilled. The universal and spiritual are intertwined because our universal yearnings reflect what the human spirit needs in order to thrive (Lee 2002c). The spiritual dimension is alive, the core of who we are, that which animates us, and evokes our reverence and awe in its mystery. Satir calls it the "life force" (Satir 1988, p.336) and the "I Am" (Satir et al. 1991, p. 172). We are therefore body-spirit, socially and historically bounded, yet imbued with dynamic creativity that can transcend the conventions of society and culture.

\section{Congruence}

Congruence is the core construct and chief aim of Congruence Couple Therapy (Lee 2002a, b, c). It involves the four As of attending, awareness, acknowledgment, and alignment. Congruence leads to greater attunement to self, others, and spirit. It creates an openness and fluidity in the way one attends to people and situations. Congruence is therefore the alignment of one's inner experience with how one lives in the world. It is living in awareness with the depths and promptings of one's spirit. In a broader sense, congruence means the acknowledgment of self, others and one's context and history.

\section{Case Illustration of Congruence Couple Therapy}

An illustrative composite has been generated from three cases of pathological gamblers and spouses selected from two research studies (Lee 2002c; Lee et al. 2006). The names and identifying information of the couples have been altered to protect their anonymity. The University of Ottawa Research Ethics Board approved the studies from which this case composite is formulated.

The composite case is structured to represent six phases in the CCT process. These are:

(1) Engaging the presenting client; (2) Aligning with the couple and assessing the couple communication and gambling; (3) Facilitating congruence; (4) Deepening experiencing;

(5) Linking the past to the present; (6) Consolidating changes. Commentary from the 
author follows each scenario, highlighting clinical observations and conceptualizations of the issues using principles in CCT. Descriptions and examples of clinical interventions are provided. Where appropriate, research evidence underlying the conceptualizations and interventions are discussed.

Phase 1: Engaging the Presenting Client

Scenario 1: Bob is a 58-year-old accountant who has taken an early retirement because of company down-sizing. He started gambling two years after retirement when a casino opened in his city. His gambling has greatly increased since his father died six months ago.

As a result, he has lost nearly all of his money from his retirement fund. He arrives at this first session alone at the urging of his wife and queries the seriousness of his gambling problem. His wife has been extremely upset upon discovering Bob's fraudulent use of her credit card and the amount of money that has been lost. Bob had a previous drinking problem, but has been sober ever since he joined Alcoholics Anonymous thirteen years ago. He refers to himself as a "recovering alcoholic". Alcoholics Anonymous takes up most of his spare time and he is a dedicated sponsor.

\section{Therapeutic Alliance}

Engaging and retaining clients in both substance abuse and gambling treatment programs present a significant challenge for clinicians (Blaszczynski and Nower 2001; Fiorentine et al. 1999; Ladouceur et al. 2001; Simpson 2004; Toneatto 2005). At the same time the therapist-client relationship is one of the most salient factors influencing therapeutic progress and outcome individually (Barber et al. 2000; Lambert and Barley 2001) and conjointly (Johnson and Talitman 1997)

Special attention needs to be paid to how the therapeutic alliance is formed from the very beginning. Through empathy and genuine regard for the client the therapist shows a desire to understand the client's concerns. Underneath the complaints and problems, the therapist searches out the positive intention, hopes, and wishes implicit in the client's presentation and gives them articulation. For example, Bob's complaint of "My wife is making it impossible for me to go home. She is so angry and accusative" is reframed into "You really wish to work things out with your wife, but she is very upset right now and you don't know what to do. Do you think it would be helpful for you both to come in and talk things out here?"

In addition, the therapist harnesses the client's motivation, not only in a rational, cognitive mode in weighing the pros and cons of treatment (Miller and Rollnick 2002; Sagorsky and Skinner 2005), but by tapping into the client's source of life energy embedded in his/her deep yearnings and desires. The therapeutic encounter takes on a spiritual dimension when the deep 'self' of the therapist intuits and hears the cry of the spirit imprisoned in the client's suffering (Satir 1988; Tam 2007). Acknowledging the 
spirit and activating the energetic centre of human longings ushers the client's movement into the therapy and healing process.

\section{Awakening Hope}

Bob who feels ashamed of himself and uncertain about his marriage, experiences a glimmer of hope in his situation when the therapist sees into his spirit of caring and the depth of his suffering. His first step in reaching out for help and his desire to talk to his wife, although he might not have known how to go about it, are acknowledged. Instead of viewing the client as the 'identified patient' and the one to blame, the therapist shows an interest in understanding the dynamics of what led to the gambling problem. The therapist presents herself as Bob's ally in validating his concerns and supporting his hopes of what he wants for his life if things were different. The attitude and values of the therapist are conveyed in the way she frames the situation and the way she speaks of the client.

\section{Setting Goals, Gaining and Structuring Commitment}

If an agency offers other formats of treatment, e.g. individual counselling, psychoeducation, and groups, this menu is presented to the client and discussed to see which of the different options would best meet his/her needs at this point. The presentation of all available options allows for informed, voluntary consent. However, this does not preclude the therapist from making a recommendation, but the choice is made in collaboration with the client. A collaborative approach enhances the client's agency and commitment to the process in his exercise of choice. If couple therapy is selected, the time horizon should be stated. A structure with an explicit time-frame alleviates the client's anxiety in knowing the extent of commitment he is making. Generally, CCT is delivered in 12-session blocks, after which time the progress of the clients is evaluated and further treatment planned if necessary. It is posited that a finite number of sessions motivates clients to work harder knowing there is an endpoint, and increases everyone's accountability because there is a review date.

Bob's concerns are formulated into immediate goals - addressing his wife's upset, understanding the factors leading to the gambling problem, and working towards abstinence or harm reduction. Concerns and complaints are readily reframed into concrete immediate and longer term therapeutic goals to give focus and direction to the therapy process.

\section{Status of the Couple Relationship}

Bob indicates although everything is in crisis at the moment, he does want to gain control of his gambling and salvage his marriage of 32 years. The therapist gains a sense from Bob what he thinks his wife's reaction would be if invited to come in for couple therapy. They explore the difficulties Bob anticipates and his fears of involving the spouse in the therapy process. Often gamblers harbor unspoken fears of being blamed and "ganged up on" by both the therapist and spouse since they feel they are the ones who had caused the 
problem. They also fear being pressured to quit gambling and make changes they may not feel ready to make. These fears need to be acknowledged. If the gambler, or sometimes the spouse, is ambivalent about having the partner in conjoint sessions, the potential benefits and risks are discussed. A short 3-session trial couple therapy can be proffered to lower the perceived risk. A simple in-session role-play with the therapist can raise the client's level of confidence in approaching the spouse in real life. The role-play can be debriefed as to what seems to work well for the client and what is less comfortable.

Phase 2: Aligning with the Couple and Assessing the Couple Communication and Gambling

Scenario 2: Bob and Nancy show up together for the next session. With some prompting Nancy begins talking about her anger towards Bob for his betrayal about his gambling and losses. She worries about her sons finding out about Bob's gambling, and the viability of their marriage. She does not think she can trust Bob again after what he has done to her and to their family. She has gone down this road before with Bob and his drinking. Bob tries to reason with Nancy and explains that he never meant to hurt her, but was afraid to tell her about his gambling for fear of her reactions. When Nancy continues to speak of her resentment, Bob shuts down and becomes silent. Nancy too becomes silent. Nancy, 55, has run a home business, and they have three sons. Nancy, though capably running the household and her business mostly on her own over the years, has struggled with anxiety and has recently been prescribed medication for it by the family doctor.

\section{Aligning with the Each Partner of the Couple}

The presence of both partners in the session allows the therapist to observe how the couple interact and communicate with each other. It also provides the opportunity for obtaining different perspectives on events. A balanced alliance with both partners is formed by giving equal attention, weight and validation to each partner'sconcernswith thecareful useof 'no blame' language in the framing and formulation of the issues. The therapist's task is to decipher the pattern that creates and maintains the problem to which both partners contribute and to map out the "pattern that connects" (Bateson 1979,p.12).

\section{The Communication Tango}

The therapist maps out how the couple's communication stances play into and reinforce each other. Bob is self-deprecating, apologetic, placating and sometimes super-reasonable with Nancy, and Nancy tends to be avoidant and super-reasonable but on occasion also blaming. Throughout their long marriage, they reported having "not half a dozen squabbles."They seldom quarreled as neither of them wanted to "rock the boat."They have "always gone separate ways"to pursue an interest or hobby that did not interest the other. When encountering differences, both tend to quickly withdraw and pretend nothing 
is wrong. It is not surprising that both feel lonely and isolated in the marriage, treating each other with surface civility to conduct their day-to-day affairs. Bob prefers to spend time with his AA fellowship members and Nancy feels uncared for, but does not make it known. However, she has exacerbated anxieties since Bob's drinking days which are still with her today. Civility is important to Nancy because of the way she was brought up, and Bob avoids any conflict, the reasons for which becomes clear when we learn about his childhood experiences. Hence, both partners are restricted to a very narrow range of communication and feel disconnected from each other. A prolonged, repeated pattern of unproductive and lack of communication leads to distress and a deepening despair as their yearnings for intimacy, understanding and connectedness remain unmet. The mutually reinforcing intrapsychic and interpersonal patterns become entrenched until they are brought to the couple's awareness in a non-blaming, descriptive manner by the therapist.

\section{Assessing the Gambling}

Assessment is a give-and-take process with the therapist alternately following and leading the client to progressively explore the various issues around gambling and the couple relationship. Individual areas that are explored include identifying any precipitating factors to the onset of problem gambling, family of origin history for each partner, their coping and self-esteem, other addictions and mental health problems, and fantasies and wishes around the gambling.

Bob started gambling 2 years after a forced early retirement and the death of his father. Family life transitions and losses are momentous events that require emotional processing and a re-constitution of one's role in the family and one's identity (Carter and McGoldrick 1988). Bob said he was "lonesome and bored"after his retirement and “didn't know what to do with myself."He was also angry at his employer. His work and his associations at work "bolstered my identity." "There was only so much you can talk about at home,"said Bob.

\section{Family of Origin History, Coping and Self Worth}

Bob's earlier history of alcohol dependency raises questions about his early life including adverse childhood events. Unresolved earlier life issues amplify the client's emotional responses when reacting to current transitions and setbacks. These early life experiences set up patterns of communication and ways of being that are reflected in the present. Therefore it is important to begin exploring Bob's usual way of coping with life's challenges, his level of self-esteem in how he regards himself, while linking these to family of origin experiences. These issues will be discussed in greater depth in Phase 5.

\section{Other Addictions}

Bob describes himself as having an "addictive personality"and has been 15 years in recovery from alcoholism. His father and grand-father both had a drinking problem. He has been active in AA and attributes his recovery from drinking to the 12-steps for which 
he is enormously grateful. Because gambling is now a legal activity and imbued with an aura of glamour, fun, excitement and upscale lifestyle, Bob was unaware of the risks of developing a problem. The criteria of DSM-IV-TR (APA 2000) for pathological gambling are used to determine the severity of Bob's gambling problem. Other measures such as the South Oaks Gambling Screen (SOGS) (Lesieur and Blume 1987) and the Gambling Symptom Assessment Scale (G-SAS) (Kim et al. 2001) are used to obtain a record of the type of gambling, frequency of gambling, money lost, and the severity of the urges and gambling preoccupying thoughts. In addition, the client is asked at various points about specific thoughts, wishes, fantasies and self-talk that accompany his urges to gamble. In the course of therapy Bob gains an increasing awareness of how gambling is related to his feelings of loneliness and a need to feel good about himself.

\section{Fantasies and Wishes}

"I deserve this. I have been working since I was 11 years old," Bob said to himself when he used to drink and when he felt the urge to gamble. Drinking and gambling give him an opportunity to be with others socially without placing great demands on him and also help him feel good for a while. He describes himself as suffering from "big shotitis," and a need to feel important which gambling satisfies. "I was always dreaming of being a big shot-big shot means a bigger, better house, and say let's go to Europe and the Orient." Feelings of defiance were also released with the gambling, "When I'm bigger and better, I'll show them!" he says to himself when he goes gambling, thoughts he has entertained as a young lad suffering derision and humiliation from his father and uncle. "When I wanted something as a kid, there was always a reason I couldn't have it," so gambling is a way he now indulges himself and makes up for childhood deprivation.

Gambling assessment commonly concentrates on the identified client, namely, the problem gambler. A systems lens looks at the interaction between the gambler and the spouse and their reciprocal dynamics of communication. While it is easy to attribute the spouse's distress to the gambling, a systems perspective delineates the pattern of interaction that feeds into their mutual distress, a pattern that could have pre-dated the gambling that has resulted in long-standing distress, isolation, and lack of support. The task now is to interrupt an intractable cycle into something constructive.

Phase 3: Facilitating Congruence

Scenario 3: Nancy begins this session criticizing Bob's over-involvement in AA which he "loves better than his own family". His previous lying leaves her wondering whether he is actually at AA in the evenings, or at the casino. As she becomes more vocal about her unhappiness, Bob becomes more anxious, apologetic and placating. Nancy, driven by her own worries and anxiety, continues to complain about Bob's unavailability now and throughout their marriage. She begins to cry. 
Interrupting Unproductive Communication Cycles and Facilitating Congruent Communication

Having delineated the couple's negative communication cycle, the therapist interrupts the unproductive cycle and prevents its escalation. The seeds of congruent communication are planted by encouraging the client to own what she is feeling, to express it, and then to reframe her blame and complaints into hopes, wishes and yearnings:

Nancy: He didn't come home until late last night. I was scared and worried. Is he at casino again? And how much is he losing this time? I am mad and so disappointed. I don't want to over-react.

Therapist: So there is a lot going on. You're feeling very vulnerable.

Nancy: I'm not allowed to be vulnerable because of how I was brought up.

Therapist: You're allowed. You are showing it now. In the past you'd have kept it hidden so no one would know. Can you now tell Bob what your wishes are?

The therapist makes a judgment call on when to engage the couple in speaking directly to each other, when to delegate a participant-observer role to the spouse, and when to interrupt. Here the therapist assists Nancy to express her wishes to Bob instead of encouraging more ventilation of complaints and worries. Bob, in turn, is asked to express the positive intention behind his behaviour of not disclosing everything for fear of worrying Nancy. Instead of superficial placation, Bob begins to talk about his feelings of loneliness and low self-worth that led him to resort to gambling as a remedy. Thus work on interpersonal communication and intrapsychic exploration and awareness occur simultaneously.

By reframing negativities into hopes and wishes in congruent communication, positive energy is brought into the room; this gently shifts repetitive dynamics that have been erosive of their relationship for a long time. Naming, acknowledging and allowing the expression of strong emotions are helpful but it needs to go beyond venting to articulating the underlying frustrated yearnings so that clients do not stay embroiled in strong, painful feelings without resolution. Strong feelings de-escalate when the client feels heard and understood in what deeply matters.

\section{Expanding the Range and Depth of Communication}

The therapist opens up the range and depth of the couple's communication with each other. Bob and Nancy make assumptions about what the other is thinking and feeling. The therapist encourages them to practise 'checking it out' with questions like "Did you mean...?,"“Is this how you see it?,"“Do you agree?,"“Do I hear you correctly?"To their surprise, their assumptions are not always accurate. In asking questions to check things 
out, they learn new information about each other and correct their assumptions and perceptions, thus initiating a whole new discovery about each other:

Therapist: Bob, it sounds like in your family, you did not experience love, or the expression of it, physically or verbally... ummm.... are you able to express love to Nancy?

Bob: Not very easily... No, not very easily at all.

Therapist: So it takes practice. You are learning to show your loving side, your tender your soft side. Why don't you ask Nancy if she feels loved by you? Can you check with her?

Bob: Oh... I know she does (laughs).

Therapist: Why don't you check with her?

Bob: (Turning to Nancy) Do I show you I love you?

Nancy: Oh... I think you have a hard time saying things... like you will jokingly say things, but even though you're joking... you mean them.... You just have a hard time expressing them.

Therapist: So... What makes it hard to show your feelings verbally, Bob?

Bob: Well... I never ever heard it. The word "love" is embarrassing!

Showing and asking for affection is difficult for Bob because of his fear of rejection, stemming from his experiences as a boy. Nancy was raised to be "good and perfect" and finds it difficult to express her "wild feelings" that she fears would put her in a bad light. Implicit rules from their families of origin about what is speakable and unspeakable, have set limits on the communication between them. Bob and Nancy practise in session to expand their communication to include: showing appreciation for each other, asking for clarification, offering new information, expressing worries and concerns, making suggestions, putting forth their hopes and wishes, and requesting help and comfort. Expanding the range and depth of communication requires the couple to step outside their normal comfort zone and practice, which once gained them acceptance and approval by their family. Hence, making habitual a new range and depth of communication is not a small feat. Facilitating congruence entails attending to what is within and finding an appropriate way to communicate it, thus linking the intrapsychic and interpersonal dimensions. 


\section{Phase 4: Deepening Experiencing}

Scenario 4: Bob and Nancy continue to struggle with their relationship, despite the fact that Bob has not been gambling for two weeks, and has been staying home more often. He has also found another job to help pay off his debts. Nancy still finds it difficult to trust Bob and harbours a great deal of resentment because of his unavailability due to his past drinking problems and outside activities. She blames herself for being so "stupid" in not noticing the signs of his gambling. With some hesitation, Bob relates the considerable stress he went through in his job when his company re-organized and his position eliminated. Previously, he has not been able or willing to share his work frustrations with his wife, because any questioning from her has been interpreted by him as a question of his competence. Neither has he shared his work setbacks with fellow AA members as he feels the need to hold up his image in order to fulfill his role as a sponsor to others.

\section{Empathy for Each Other's Pain}

As the couple becomes more engaged and trusting in the couple therapy process, deeper emotions and disclosures come to the fore. Until now, Bob and Nancy each experienced stress and struggles on their own, unable to lend each other support. Their unresolved feelings and frustrations in the relationship grew into resentment over the years. They are together but isolated. Trusting the safety in the therapy process, the couple venture into more intimate disclosures. Each partner gains a deeper sense of how his/her way of being and behaving impacts on the other, of which they hitherto had been unaware. This awareness of not only self, but of the other in their inner experience is an important constituent of congruence. An appreciation of the humanity of oneself and of one's spouse develops.

Attentive listening and demonstrations of empathy are humanizing processes. The therapist opens up a space for exploration of difficult past and present experiences in the session. At this stage, the therapist slows down the process and deepens the therapy to a more experiential, bodily felt level to allow expression of the hurts, disappointments, and fears each partner suffers, verbally and sometimes through tears. Previous inaccessible and unexpressed emotions, thoughts and yearnings had been detoured into gambling as an outlet-“I'll show them!"“No one is going to tell me what to do!" Internal dynamics of thoughts, feelings, expectations and yearnings find vicarious expression through gambling when direct, clear avenues for congruent expression are absent.

Nancy talks about how Bob's gambling and previous drinking affected her. As Nancy begins to experience some of her vulnerabilities and starts to express them, she gradually shifts from her role as the "strong one" who holds everything together. "I come across as capable but in reality I'mhurt. I'm devastated but I'm not inclined to show it. I'm more inclined to show anger," says Nancy. She used to think, "Whatever happens, I can 
manage." She now makes requests for help from Bob. Bob is surprised to see that Nancy has a soft and vulnerable side. This shift in perception allows the couple to achieve more mutuality in the relationship in reciprocal care and consideration to break out of rigid "overfunctioning-underfunctioning" roles.

\section{Noticing and Appreciating Minimal Change}

High levels of expectations can blind one to the partner's changes that are taking place. The therapist calls Nancy to notice minimal changes in Bob, such as his willingness to share about a misunderstanding with his mother. Showing appreciation for small changes not only reinforces positive changes, but also nourishes a couple's relationship. Expressing appreciation is initially awkward for Nancy who has high standards and is not used to expressing praise or appreciation. The therapist acts as a role model.

\section{Self Worth and Universal-spiritual Affirmations}

Both Bob and Nancy do not adequately appreciate their own worth-Bob in feeling he needs to "prove" himself and his competence; Nancy in criticizing herself in having been so "stupid" as to have missed Bob's signs of gambling. More compassionate and selfaffirming messages are induced through visualization and meditation to bring about heightened receptivity. For example, the therapist uses the following visualization to enlarge Bob's positive image of self:

So there are two pictures-the picture of yourself you've kept all these years-not lovable, shy, not liked by your father. It's black and white and old. Fade it and let it shrink in size. Now there's a new picture-in technicolour-and you are good-looking, sociable and likeable. Stay with this picture for a while-you are loving, and a good father to your children even more than you knew...let this picture get bigger...Take a deep breath...Now give yourself a message of appreciation for simply being you and know that you are lovable.

Valuing and cherishing himself and his essence promotes a greater sense of agency in Bob and reduces his attributions of events to others, to "luck" and "fate." To realize and affirm one's intrinsic worth is an aspect of spirituality.

Phase 5: Linking the Past to the Present

Scenario 5: An exploration of family of origin influences reveals that Bob's father was as taskmaster who ran a tight ship" with a drinking problem. Bob describes his father "a "perfectionistic, critical and morose" with high expectations and lack of praise for the children. His older brother was the favoured child because he was handy with tools like his father. Bob, being the more "bookish" one in the family, was an overlooked middle child. He had to help out with different chores as a child with his father's family business. Bob and his father were distant when he died and they had never been very close. Bob's mother catered to his father and took a passive role in the family. He witnessed his father make berating, depreciating remarks to her on many topics during dinner conversations. Nancy was the oldest in her family and had to look after her younger siblings. There was little time for fun and play. Her mother had numerous medical problems. She admired her father, although he was often absent from home because of the nature of his job. Nancy's mother often talked about her father in a negative fashion. Affection was seldom expressed verbally or phvsicallv. Nancv learned to be steadv. dutiful and to excel in school. 


\section{Finding the Pattern that Connects}

Communication and coping patterns learned early from one's family of origin are often replayed in present family relationships. The family map or genogram for each partner begins as a sketch which gets filled out and elaborated as the sessions progress. The visual representation of the relationships, communication stances, critical events, descriptions of each family member on a flip chart supplies a clear common reference for both clients and therapist.

Bob grew up with little validation of his gifts and abilities. He was berated and given messages of his incompetence by both his father and uncle, who was involved in a family business with Bob's father. When not in school, Bob was expected to help out. He had distanced himself from the pain of his childhood throughout his life, with unspoken memories of physical violence including being attacked by his uncle with a tool, the scar of which is still visible this day. He had not explored his excruciating childhood experiences in AA despite his long involvement with the group. It was only recently that he became aware of his resentment towards his father and uncle and admitted to the severe physical and emotional abuse he suffered. Connecting with the painful feelings associated with the abuse and the distorted self-image was difficult for Bob. This level of work entails skilled sensitivity and timing by the therapist:

Therapist: If you could see in your mind's eye this little boy without front teeth, wearing hand-me-down clothes, who wasn't given much attention or appreciation by those adults around him, if you could just see him in front of you. Could you see him now if you close your eyes?

Bob: Oh yes, um-hm...

Therapist: What would you like to say to him?

Bob: Well, I...I don't know...I blame my father... He was a tyrant...

Therapist: So what do you want to say to your father?

Bob: I said lots to my father...

Therapist: Let us hear it...

Bob: He and I used to lock horns. I was 12 when he beat me up for no reason...

Therapist: What would you do for that little boy today if you were on the scene?

Bob: I'd have my arm around his [father's] neck. 
Therapist: Don't you DARE do it!

Bob: Yeah!

Therapist: What would you do for the little boy? [Seeing that Bob was having difficulty acknowledging and comforting himself, the therapist turned to Nancy.]

Nancy, what would you do for the little boy?

Nancy: Oh, hug him [loudly]... I would have hugged him.

Therapist: Bob, could you just close your eyes for a minute, it's really important. Can you see the little boy who was left alone and unprotected?

Bob: Um-hm.

Therapist: Could you open up your arms to him? [Therapist modelled.]

Bob had difficulty fully entering the experiential moment with his father and the therapist recruited Nancy into the scene for support and validation of Bob. With a lowly sense of self, Bob had to constantly prove himself in his school and work performance. "Conceit will get you nowhere," he was taught. Bob starts to realize the deep resentment he harbours towards his father:

Bob: Oh yeah, well, later on in life when I was 15, 16 years old I took nothing off him. Therapist: Know that it's him you want to get even with, not yourself. So you're not going to use that anger and turn it onto yourself.

Bob: Well he did give me the feeling that I wasn't capable of doing anything.

Therapist: But it's not you, is it?

Bob: No, looking back I know I did good work. I did hard work. I was complimented by many people for my work.

Bob's family of origin experiences explain his pattern of keeping feelings and stress to himself rather than confiding in his wife. Thus, he perpetuated in his life the feeling that there was no one to turn to in times of stress. Healing from childhood wounds allows Bob to realize that he is not to be blamed as a child, to understand the suffering of his "abusers" who also grew up in wretched circumstances, to reclaim his own giftedness and worth, and to note the values he held on to throughout the years despite the many trials and tribulations, such as his sense of responsibility and hard work. "I have done something right in my life," Bob acknowledges to himself the first time. With a higher sense of self worth, Bob becomes more congruent in his communication with Nancy and others at work, to make requests, and to say "no" to excessive demands and pressures. He 
learns to respect himself.

As a witness to Bob's story, Nancy is surprised to learn of Bob's bleak childhood. She is visibly moved by his story. Prompted by the therapist, Nancy is able to say to Bob, "You are a good boy. There is nothing wrong with you. I want to hold you." Although overtly Nancy's history is not as traumatic, she begins to realize that she has assumed the role of a care-giver early in life with responsibilities for her siblings and as mother's 'helper.' She knew little about play and relaxation. Her mother's ailments caused her worries and anxieties. Nancy's relationship with her father has been a mix of adulation and disappointment; he is there, but he is absent. She also has not learnt good examples of open, congruent communication from her parents. Unresolved feelings of neglect and loneliness as a child, over-functioning, and her anxiety have influenced how she conducted her relationship with Bob.

Bob and Nancy develop empathy, compassion and appreciation for each other in hearing and witnessing each other's pain. Their deepened understanding of human vulnerability and resiliency from their sharing brings about a new perception of each other, leading to greater sensitivity in the way they speak to and treat each other. Thus we see the intertwining of intergenerational, intrapsychic, interpersonal, and the universal-spiritual dimensions in the work with this couple.

\section{Finding the Treasures}

Families also bequest gifts and resources to the children. Acknowledging not only the hurts but also the gifts from one's family of origin is important and raises one's worth and connectedness in the world. Bob learned to be a hard, conscientious worker who has strongly developed analytic abilities and family values. Nancy is a capable manager who runs the household and home business. To accept their parents as human beings with their own history, their strengths and limitations, to appreciate their efforts with the knowledge and skills available to them in coping with life's difficulties, allows Nancy and Bob to appreciate and accept ourselves. This adds to their base of self worth through the honouring of their ancestral past. Past and present are permeable. CCT's focus is on the present and future, with the knowledge that what is different in the present loosens the grip of the past. 
Phase 6: Consolidating Changes

Scenario 6: Two months into therapy, Bob and Nancy had a "major fallout" when Bob "disappeared" one evening. This generated a lot of anxiety for Nancy who happened to also have had a "bad day". Despite the reawakening of old feelings of anxiety and defensiveness, the couple attempted to "step back" to take stock of the situation and their own reactions, and chose a more congruent way of sorting out their conflict. They started to take charge of their reactions, communication and the relationship.

Bob and Nancy have been spending more time together. In fact, they planned a weekend away at a resort, the first one in 22 years. Because Bob is home more often now that the criticisms from Nancy have decreased, Nancy is less worried about Bob's gambling, and her mood has changed for the better. Bob is able to discuss with Nancy his worries about his widowed mother who may need to move into a retirement home. Bob has become more aware of the triggers that gave rise to his urges to gamble, e.g. after a conflict. Because he is now able to give himself more credit for things that go well, he attributes his successes less to "luck." His increased self-awareness of his interior experience, such as his thoughts and feelings, allows him to speak congruently to Nancy about his worries. This lowers the stress burden he has to carry. Although Bob still experiences urges to go to the casino, these urges are much lower in intensity and frequency and much more manageable.

\section{Setbacks}

Couples do have setbacks and crises even after some deep work has been done in therapy. The difference is that they are now able to bring their new intrapsychic, interpersonal, and spiritual resources to bear on the problem. In other words, they now draw on their expanded coping capacity and are therefore more resilient in the face of stress and life's challenges.

\section{Consolidating New Outcomes}

When Bob and Nancy report that new patterns have emerged, the therapist reflects these patterns back to them, not only in terms of outcomes, but by inviting them to explore the process that led to these outcomes. "How did you manage to get there?" Delineating the process heightens the clients' awareness of the interplay of their intrapsychic and interpersonal processes that feed into a new positive loop. Bob's fantasies of gambling revolve around feeling "big" and important and getting even with his father. As he strengthens his self worth and works through the trauma of his severe childhood physical and emotional abuse, he reports better able to deal with his gambling urges when they 
arise. The improved communication between the couple takes care of some of Bob's fear of "boredom" and gives him added support in times of stress. To reinforce and anchor these positive movements, a method of circular questioning elicits each partner's observations of process and outcomes. The therapist is a participant-observer to this round of circular questioning and holds up a mirror to the couple's changes and progress.

\section{Future Plans}

At the end of 12 sessions, Bob reports the following:

Overall, there has been a large improvement in every respect of my life. I was able to explain my feelings to Nancy. I think she understands. I learnt how Nancy feels. I have to admit that I was hard on myself and my self-esteem. The therapy keyed in on my feelings about my childhood and got me to talk about it. We are getting better every day.

Some family systems issues related to pathological gambling may require more than 12 sessions of therapy to work through. While acknowledging the success achieved and the progress made, remaining issues that each couple feel they need to still work on are identified. Nancy experiences some big swings in her sense of well-being and feelings of anxiety. She expresses the desire to have some sessions to talk about the effects of Bob's past drinking problems on her. The strength of her feelings about past hurts continue to surface, feelings that she had kept under tight control before. There is also disagreement between the couple about whether Bob should disclose his gambling to AA and their children. Further sessions were negotiated with this couple. Depending on the couple, referrals can be made for more in-depth individual and/or couple work as appropriate after a 12-session block. Or couples are given a chance to practise new patterns on their own, monitored by periodic check-ins with the therapist for support and maintenance.

\section{Conclusion}

Congruence Couple Therapy is structured as 12 one-hour weekly sessions. These 12session blocks consist of a compact set of interventions and provide a point of evaluation at which time further sessions can be negotiated as necessary. The foregoing case composite represents six phases in working with a couple and serves to discuss the key concepts, values and interventions of Congruence Couple Therapy in pathological gambling treatment.

CCT integrates systemic, humanistic, existential, experiential and social constructionist philosophical premises. The four-dimensional conceptual model of the person provides a map to guide interventions; at the same time CCT is sufficiently open and flexible for therapists to decide what entry point to take among the four dimensions to help the partners in the couple relationship move towards congruence and healing. Like a house with many doors, a point of entry can be intrapsychic, interpersonal, intergenerational or universal- spiritual, depending on the opportune moment and clients' readiness. Each change then leverages other changes in the system. Thus CCT interventions ideally link at least two dimensions while the conceptual model of the person keeps the four inter- 
related dimensions in view. Since the changes involve shifts in multiple dimensions, one would expect that CCT resultant changes are more stable in the new systemic configuration than if only an isolated change is made.

While pathological gambling is the presenting problem and remains a focal issue in therapy, gambling is dealt with in the context of the gambler's broader and deeper life concerns. Hence, health is more than the absence of a symptom and extends to opening up the client's wider capacity and freedom to reach for cherished hopes and aspirations. The horizon of CCT goes beyond abstinence and 'recovery' to the pursuit of the fullness of life.

This paper presents six key movements or phases commonly encountered in CCT in pathological gambling. A number of clinical issues invite further attention such as ways in which couple impasses are resolved and how the breach in couple relationship is healed. The use of couple therapy as an effective intervention for 'individual' disorders has been noted as a fertile area for clinical research (Johnson 2003). Individual and relationship problems intersect and reciprocally impact each other in multiple ways (FalsStewart et al. 2000; Gurman 2001; Johnson 2002; Halford et al. 1999). Utilizing interpersonal dynamics as leverage for individual change and establishing supportive couple relationships for individual healing pose new options for gambling treatment conceptualization and intervention.

As CCT continues to develop through iterative cycles of training, practice, and research, the relationship between CCT's interventions in the four dimensions and treatment outcomes will be further elucidated. Together with outcome studies, equally important is research on the process and mechanisms of change to refine CCT's systemic interventions and clinical decisions. Outcome and process research will inform CCT's continuing evolution for pathological gambling treatment and its potential applications to other addictions and issues in mental health.

Acknowledgments The author gratefully acknowledges funding from the Ontario Problem Gambling Research Centre for the two empirical studies on Congruence Couple Therapy from which this composite case is drawn. Special thanks to Bev West, David Gregory, Jason Solowoniuk and Florence Loh for their editorial assistance and comments in the preparation of this manuscript.

\section{References}

American Psychiatric Association. (2000). Diagnostic and Statistical Manual of Mental Disorders ( $4^{\text {th }}$ ed.) (Text Revision). Washington, DC: Author.

Anderson, H. \& Goolishian, H. (1988). Human systems as linguistic systems: Preliminary and evolving ideas about the implications for clinical theory. Family Process, 27, 371-393.

Banmen, J. (1994). Figure: The personal iceberg of the Satir Model. In handout distributed at workshop, A model for change: The Satir experience, April 10-15, 1995, Villa Maria, St. Norbert, Manitoba.

Barber, J. P., Connolly, M. B., Crits-Cristoph, P., Gladis, L., \& Siqueland, L. (2000). 
Alliance predicts patients' outcome beyond in-treatment change in symptoms. Journal of Consulting and Clinical Psychology, 68, 1027-1032.

Bateson, G. ( 1972). Steps to an ecology of mind. New York: Ballantine.

Bateson, G. (1979). Mind and nature, a necessary unity. Toronto: Bantam Books.

Blaszczynski, A., \& Nower, L. (2001). A pathways model of problem and pathological gambling. Addiction, 97, 487-499.

Blaszczynski, A., Steel, Z. (1998). Personality disorders among pathological gamblers, Journal of Gambling Studies, 14(1), 51-71.

Berger, P., \& Luckmann, T. (1967). The social construction of reality. Garden City, NY: Doubleday.

Bowen, M. (1978). Family therapy in clinical practice. New York: Aronson Press.

Brown, P. D., \& O’Leary, D. (2000). Therapeutic alliance: Predicting continuance and success in group treatment for spouse abuse. Journal of Consulting and Clinical Psychology, 2, 340-345.

Brubacher, L. (2006). Integrating emotion-focused therapy with the Satir model. Journal of Marital and Family Therapy, 32(2), 141-153.

Ciarrocchi, J. W., \& Hohmann, A. A. (1989). The family environment of married male pathological gamblers, alcoholics, and dually addicted gamblers. Journal of Gambling Behavior, 5(4), 283-291.

Cain, D. J. (2002). Defining characteristics, history, and evolution of humanistic psychotherapies. In D.J. Cain \& J. Seeman (Eds.), Humanistic psychotherapies: Handbook of research and practice (pp. 3-54). Washington, DC: American Psychological Association.

Carter, B. \& McGoldrick, M. (Eds) (1988). The changing family life cycle: A framework for family therapy. New York: Gardner Press.

Coman, G. J., Burrows, G. D., \& Evans, B. J. (1997). Stress and anxiety as factors in the onset of problem gambling: Implications for treatment. Stress Medicine, 13(4), 235-244.

Crisp, B. R., Thomas, S. A., Jackson, A. C., \& Thomason, N. (2001). Partners of problem gamblers who present for counseling: Demographic profile and presenting problems. Journal of Family Studies, 7, 208-216.

Darbyshire, P., Oster, C., \& Carrig, H. (2001a). Children of parent(s) who have a gambling problem: A review of the literature and commentary on research approaches. Health and Social Care in the Community, 9(4), 185-193.

Darbyshire, P., Oster, C., \& Carrig, H. (2001b). The experience of pervasive loss: Children and young people living in a family where parental gambling is a problem. Journal of Gambling Studies, 17(1), 23-45.

Dickson-Swift, V. A., James, E. L., \& Kippen, S. (2005). The experience of living with a problem gambler: Spouses and partners speak out. Journal of Gambling Issues, 13, Retrieved October 6, 2007 from http://www.camh.net/egambling/issue13/index.html

Elkins, D. N. (2001). Beyond religion: Toward a humanistic spirituality. In K. J. Schneider, J. F.T. Bugental \& J. F. Fraser (Eds), The handbook of humanistic psychology: Leading edges in theory, research, and practice (pp. 201-212). California: Sage Publications. 
Fals-Stewart, W., O’Farrell, T.J., Feehan, M., Birchler, G. R., Tiller, S., \& McFarlin, S.K. (2000). Behavioral couples therapy versus individual-based treatment for male substance abusing patients: An evaluation of significant individual change and comparison of improvement rates. Journal of Substance Abuse Terament, 18, 249-254.

Fiorentine, R., Nakashima, J. \& Anglin, D. M. (1999). Client engagement in drug treatment. Journal of Substance Abuse Treatment, 17(3), 199-206.

Frankl, V. (1953). Man's search for meaning. Boston, MA: Beacon.

Franklin, J., \& Ciarrocchi, J. (1987). The team approach: Developing an experiential knowledge base for the treatment of the pathological gambler. Journal of Gambling Behavior. 3(1), 60-67.

Gendlin, E. T. (1974). Experiential psychotherapy. In F. J. Corsini (Ed.), Current Psychotherapies (3rd edition, pp. 317-352). Illinois: F.E. Peacock.

Gendlin, E. T. (1981). Focusing ( $2^{\text {nd }}$ ed.). New York: Bantam.

Gergen, K. (1985). The social constructionist movement in modern psychology. American Psychologist, 40, 266-275.

Grant-Kalischuk, R., Nowatzki, N., Cardwell, K., Klein, K., \& Solowoniuk, J. (2006). Problem gambling and its impact on families: A literature review. International Gambling Studies, 6(1), 31-60.

Gurman, A. (2001). Brief therapy and family and couples therapy: An essential redundancy. Clinical Psychology: Science \& Practice, 8, 51-65.

Halford, K. W., Bouman, R., Kelley, A., \& Young, R. (1999). Individual psychopathology and marital distress: Analysing the association and implications for therapy. Behavior Modification, 23, 179-216.

Heineman, M. (1994). Compulsive gambling: Structured family intervention. Journal of Gambling Studies, 10 (1), 67-76.

Heinemann, M. (2001). Losing your shirt: Recovery for compulsive gamblers and their families $\left(2^{\text {nd }}\right.$ ed.). Center City, MN: Hazelden.

Hendricks, M.N. (2002). Focusing-oriented/experiential psychotherapy. In D.J. Cain \& J. Seeman (Eds), Humanistic psychotherapies: Handbook of research and practice (pp. 221-251). Washington, DC: American Psychological Association.

Johnson, S. M. (2002). Emotionally focused couple therapy for trauma survivors: Strengthening attachment bonds. New York: Guilford Press.

Johnson, S. M. (2003). The revolution in couple therapy: A practitioner-scientist perspective. Journal of Marital and Family Therapy, 29(3), 365-384.

Johnson, S. M., \& Talitman, E. (1997). Predictors of success in emotionally focused marital therapy. Journal of Marital and Family Therapy, 23, 135-152.

Kim, S.W., Grant, J. E., Adson, D. E., \& Shin, Y.C. (2001). Double-blind naltrexone and placebo comparison study in the treatment of pathological gambling. Biological Psychiatry, 49(11), 914-921.

Ladouceur, R., Gosselin, P., Laberge, M., \& Blaszczynski, A. (2001). Dropouts in clinical research: Do results reported in the field of addiction reflect clinical reality? The Behavior Therapist, 24, 44-46.

Lambert, M. J., \& Barley, D. E. (2001). Research summary on the therapeutic relationship and psychotherapy outcome. Psychotherapy, 38, 357-361. 
Lee, B.K. (2002a). Well-being by choice not by chance: An integrative, system-based couple treatment model for problem gambling. Final Report. Guelph, ON: Ontario Problem Gambling Research Centre.

Lee, B. K. (2002b). Congruence in Satir's model: Its spiritual and religious significance. Contemporary Family Therapy, 24(1), 57-78.

Lee, B. K. (2002c). Development of a Congruence Scale based on the Satir Model. Contemporary Family Therapy, 24(1), 217-239.

Lee, B. K. (2002d). Evoking the universal human family in public acts of healing: Jesus of Nazareth and Virginia Satir. Pastoral Sciences, 21 (2), 263-286.

Lee, B. K. (2003, December). Well-being by choice not by chance: A family systems model for conceptualization and treatment of pathological gambling [Abstract and Poster]. Final Program of the 4th Annual Conference on Gambling Addiction, National Centre for Responsible Gambling and the Institute for Research on Pathological Gambling and Related Disorders, Harvard Medical School, Las Vegas, Nevada.

Lee, B. K., Rovers, M.W., \& MacLean, L. (2006). Training counsellors in Congruence Couple Therapy: A controlled evaluation study. Final Report. Ontario Problem Gambling Research Centre, Guelph, Ontario.

Lee, B.K., \& Nixon, G. (2007). Integrating narrative and symbolic representation in experiential process for identity change. Manuscript submitted for publication (copy on file with authors).

Lee, B. K., \& Rovers, M. (2008). 'Bringing torn lives together again': Effects of the first Congruence Couple Therapy application to clients in pathological gambling. International Gambling Studies, 8 (1), 113-129.

Lee, B.K., Rovers, M., \& MacLean, L. (2008). Training problem gambling counsellors in Congruence Couple Therapy: Evaluation of training outcomes. International Gambling Studies, 8(1), 95-112.

Lesieur, H. R., \& Blume, S. B. (1987). South Oaks Gambling Screen (SOGS): A new instrument for the identification of pathological gamblers. American Journal of Psychiatry, 144, 1184-1188.

Lightsey, O. R., \& Hulsey, C. D. (2002). Impulsivity, coping, stress, and problem gambling among university students. Journal of Counseling Psychology, 49, 202211.

Lorenz, V. (1987). Family dynamics of pathological gamblers. In T. Galski (Ed.), The handbook of pathological gambling (pp. 71-88). Springfield, IL: Charles Thomas.

Lorenz, V. C., \& Yaffee, R. A. (1988). Pathological gambling and psychosomatic, emotional and marital difficulties as reported by the spouse. Journal of Gambling Behavior, 4, 13-26.

Lorenz, V. C., \& Yaffee, R. A. (1989). Pathological gamblers and their spouses: Problems in interaction. Journal of Gambling Behavior, 5, 113-126.

Makarchuk, K., Hodgins, D. C., \& Peden, N. (2002). Development of a brief intervention for concerned significant others of problem gamblers. Addictive Disorders and Their Treatment, 1, 126-134.

Maslow, A. (1968). Toward a psychology of being (2nd ed.). Princeton, NJ: Van Nostrand. 
May, R. (1953). Man's search for himself. New York, NY: Dell.

May, R. (1981). Freedom and destiny. New York, NY: Norton.

McCormick, R.A. (1994). The importance of coping skill enhancement in the treatment of the pathological gambler. Journal of Gambling Studies, 10(1), 77-86.

McCown, W. G. (2004). Treating compulsive and problem gambling. In R. H. Coombs (Ed.), Handbook of addictive disorders: A practical guide to diagnosis and treatment (pp. 161-194). Hoboken, NJ: John Wiley \& Sons.

McCown, W.G., \& Chamberlain, L.L. (2000). Best possible odds: Contemporary treatment strategies for gambling disorders. New York: John Wiley \& Sons.

Meador, B.D., \& Rogers, C.R. (1984). Person-Centered Therapy. In R. Corsini (Ed.), Current psychotherapies (3rd edition, pp. 142-195). Itasca, Illinois: F.E. Peacock Publishers, Inc.

Miller, W.R., \& Rollnick, S. (2002). Motivational interviewing: Preparing people for change $\left(2^{\text {nd }}\right.$ ed.). New York: The Guildford Press.

Monaci, M. G., Scacchi, L., \& Gervasoni, M. (2005). Emotions and coping in gambling: A comparison between occasional and pathological gamblers. [Italian]. Bollettino di Psicologia Applicata, 245(1), 3-17.

Nathan, P.E. (2005). Methodological problems in research on treatments for pathological gambling. Journal of Gambling Studies, 21(1), 111-116.

Nichols, M. P., \& Schwartz, R. C. (1995). Family therapy: Concepts and methods $\left(3^{\text {rd }}\right.$ ed.). Boston, MA: Allyn and Bacon

Oakley-Browne, M. A., Adams, P., \& Mobberley, P. M. (2004). Interventions for pathological gambling (The Cochrane Library, Issue 1). Chichester, UK: John Wiley \& Sons.

Perls, F., Hefferline, R., \& Goodman, P. (1951). Gestalt therapy: Excitement and growth in the human personality. London: Souvenir Press.

Petry, N.M. (2005). Pathological gambling: Etiology, comorbidity, and treatment. Washington, DC: American Psychological Association.

Petry, N. M., Litt, M. D., Kadden, R., \& Ledgerwood, D. M. (2007). Do coping skills mediate the relationship between cognitive-behavioral therapy and reductions in gambling in pathological gamblers? Addiction, 102, 1280-1291.

Petry, N. M., \& Steinberg, K. L. (2005). Childhood maltreatment in male and female treatment-seeking pathological gamblers. Psychology of Addictive Behaviors, 19(2), 226-229.

Petry, N. M., Stinson, F. S., \& Grant, B. F. (2005). Comorbidity of DSM-IV pathological gambling and other psychiatric disorders: Results from the National Epidemiologic Survey on Alcohol and Related Conditions. Journal of Clinical Psychiatry, 66(5), 564-574.

Remen, N., May., R., Young, D., \& Berland, W. (1985). The wounded healer. Saybrook Review, 5(1), 84-93.

Rogers, C. (1961). On becoming a person: A therapist's view of psychotherapy. Boston, MA: Houghton Mifflin.

Sagorsky, L., \& Skinner, W. (2005). Using motivational interviewing with clients who have concurrent disorders. In W. J. W. Skinner (Ed.) Treating concurrent disorders: A guide for counsellors. Toronto, ON: Centre for Addiction and Mental Health. 
Satir, V., Banmen, J., Gerber, J., \& Gomori, M. (1991). The Satir model: Family therapy and beyond. Palo Alto, CA: Science \& Behavior Books.

Satir, V. (1988). The new peoplemaking. Mountain View, CA: Science and Behavior Books.

Savron, G., Pitti, P., \& DeLuca, R. (2003). Mood states and personality traits in pathological gambling sample and their family members. Rivista di Psychiatria, 38(5), 247-258.

Scherrer, J. F., Xian, H., Kapp, J. M., Waterman, B., Shah, K. R., Volberg, R., \& Eisen, S. A. (2007). Association between exposure to childhood and lifetime traumatic events and lifetime pathological gambling in a twin cohort. Journal of Nervous and Mental Disease, 195(1), 72-78.

Seeman, J. (2002). Looking back, looking ahead: A synthesis. In D.J. Cain \& J. Seeman (Eds), Humanistic psychotherapies: Handbook of research and practice (pp. 617636). Washington, DC: American Psychological Association.

Sexton, T.L., Weeks, R.W., \& Robbins, M.S. (Eds) (2003). Handbook of family therapy. New York: Brunner-Routledge.

Simpson, D.D. (2004). A conceptual framework for drug treatment process and outcomes. Journal of Substance Abuse Treatment, 27, 99-121.

Steinberg, M. (1993). Couples treatment issues for recovering male compulsive gamblers and their partners. Journal of Gambling Studies, 9(2), 153-167.

Tam, E. P.C. (2007). A psycho-spiritual approach to Christian spiritual direction based on the Satir model of therapy. Hong Kong: Tao Fong Shan Christian Centre.

Tillich, P. (1967). Systematic theology (3 volumes). Chicago: University of Chicago Press.

Toneatto, T. (2005). A perspective on problem gambling treatment: Issues and challenges. Journal of Gambling Studies, 21(1), 75-80.

Toneatto, T., \& Ladouceur, R. (2003). Treatment of pathological gambling: A critical review of the literature. Psychology of Addictive Behaviors, 17(4), 284-292.

Toneatto, T., \& Millar, G. (2004). Assessing and treating problem gambling: Empirical status and promising trends. Canadian Journal of Psychiatry, 49(8), 517-525.

Vander Bilt, J., \& Franklin, J. (2003). Gambling in a familial context. In H. J. Shaffer, M. N. Hall, J. Vander Bilt, \& E. George (Eds.), Futures at stake: Youth, gambling, and society (pp. 100-125). Reno, NV: University of Nevada Press.

Von Bertalanffy, L. V. (1968). General systems theory. New York: George Braziller.

Watzlawick, P., Weakland, J., \& Fisch, R. (1974). Change: Principles of problem formation and problem resolution. New York: Norton.

Wiebe, J., Single, E., \& Falkowski-Ham, A. (2001). Measuring gambling and problem gambling in Ontario. Ontario: Canadian Centre on Substance Abuse and Responsible Gambling Council.

White, M. \& Epston, D. (1990). Narrative means to therapeutic ends. New York: Norton. 